\title{
Concrete Consciousness \\ A Sartrean Critique of \\ Functionalist Accounts of Mind
}

Joel W. KRUeGer

\section{Introduction}

In this essay, I examine Sartre's relevance to some issues in contemporary philosophy of mind ${ }^{1}$. Specifically, I argue that Sartre's development of his notion of pre-reflective consciousness can be summoned to offer a general challenge to contemporary functionalist accounts of mind, broadly construed. In virtue of the challenge Sartre offers these contemporary functionalist accounts and the richness of his phenomenological analysis, I conclude that his voice needs to be included in ongoing debates over the nature of consciousness. (At present, Sartre scarcely receives more than a passing reference in most introductory philosophy of mind anthologies, if he's mentioned at all). Moreover, I argue that Sartre's model of consciousness needs to be acknowledged as an alternative to the general functionalist views of mind currently dominating Anglo-American debates, as it rightly resituates embodied and embedded phenomenal consciousness at the center of discussions of mind. However, I conclude the essay by discussing a way in which Sartre's notion of prereflective consciousness is incomplete. I do this by sketching out a way to enrich Sartre's still overly-cognitivist notion of pre-reflective consciousness by situating it within the sensorimotor capacities of embodied action. I demonstrate how this deepened formulation of prereflective consciousness (rather, a "bodily self-awareness") is more consonant with the phenomenology of our lived experience.

\section{Functionalism Defined}

I begin by tracing the general contours of a functionalist account of mind. In his characteristically understated manner, John Searle has 
written that "If you are tempted to functionalism, I believe you do not need refutation, you need help" (1992: 9). Happily, one does not have to endorse Searle's judgment about the psychological wellbeing of those drawn to functionalist theories of mind to recognize some of their limitations. As we'll see, Sartre's analysis of the bodily nature of consciousness is quite helpful in this regard.

So what is a functionalist account of mind? Simply put, functionalism-unlike its philosophical ancestor, behaviorism-concedes that mental states are "inner" or intracranial states of some sort, and that they are not merely reducible to publicly observable "outer" behavioral states or dispositions to behave in certain ways. (This of course was the behaviorist gloss of the mental, now very much out of favor). But functionalism claims that, although different mental states are inner states, no properties intrinsic to different mental states individuate them as being the sorts of mental states that they are. Rather, the relational properties of a given state are actually what make it the sort of state that it is. In other words, nothing intrinsic to mental states accounts for the unique "feel" that commonsense introspection and the grammar of folk psychology ${ }^{2}$ seems to indicate different sorts of mental states as having (e.g., "what its like" to remember a childhood trip to the circus versus "what its like" to have a visual experience of a sunset, work out a logical proof, or drink a single malt scotch).

In short, functionalism offers an abstract computational characterization of mind independent of its neurobiological implementation. It claims that mental states are individuated by their functional or causal relations: a state-token's causal relations to stimulus inputs, other internal mental states, and behavioral or motor outputs. These relational properties individuate all mental states. And it is these relational properties that tell us what a mental state is. Thus, generally speaking, mental states correspond to functional states-states that exhibit a certain function within the larger mental economy of a cognitive system. Their distinctive causal role, or their embeddedness within the larger causal network of other states and the organism's patterns of behavior, is what individuates particular mental states and their properties. Using the experience of pain as an example, Hilary Putnam (who along with David Armstrong and David Lewis was an early proponent of functionalism) writes the following:

... pain is not a brain state, in the sense of a physical-chemical state of the brain (or even the whole nervous system), but another kind of state entirely. I propose the hypothesis that pain, or the state of being in pain, is a functional state of the whole organism. ([1967] 1991: 199) 
To be in pain, according to Putnam, is therefore not simply to be in a particular mental state that "always lead[s] to one and the same physical "correlate" of pain" (Putnam [1967] 1991: 201). Nor is it the experience of being in a certain mental state that possesses an intrinsic qualitative or subjective property that marks that state as a pain-feeling state. Rather, a pain-feeling organism is defined as such by the functional organization of the whole organism: again, the causal-functional relations of sensory inputs (searing pain of hand placed on the burner; faint smell of burning flesh), relations to other states (strong desire to end hand-on-the-burner pain; embarrassment of having burnt oneself in front of one's date), and behavioral outputs (wild flapping of seared hand; rushing to sink to douse seared hand in water while maintaining some semblance of dignity in front of date).

Mental states are thus functional states. And Putnam argued that they are in this way similar to the logical or functional states of a computer program (or Turing machine functional states, to be more precise) (Putnam [1967] 1991: 199). Computer software can be run on any number of different hardware configurations. Similarly, the program routines or input-output sequences constitutive of mentality, too, can be instantiated within many different forms of biological "hardware." Given this relatively abstract view of mind as constituted by causal-functional relations, Putnam thus offered the claim that minds are multiply realizable. On this view, the actual materials making up the cognitive system are irrelevant. As long as the materials of a cognitive system are arranged in the appropriate functional or causal relations, any appropriately-arranged system can potentially be conscious (just as it is logically possible to make a functional clock out of carrots). The mental properties constitutive of consciousness are not, strictly speaking, therefore necessarily tied to the physical properties of the brain or any properties intrinsic to mental states. This consequence of computational functionalism was seen as an important advancement over the type-identity view of mind-brain relations, which insisted that mind and brain are one and the same. Type-identity theorists had faced the difficult problem of having to deny the logical and metaphysical coherence of the possible existence of humanlike minds-conscious aliens, silicon-based organisms, AI constructs - that are nonetheless not identical with humanlike brains. Computational functionalism purported to offer a characterization of mentality that did justice to the uniquely inner nature of mind (contra behaviorism) while avoiding the conceptual and metaphysical pitfalls of identity theories. 
The above gloss is admittedly painted with broad strokes. And it is limited to a discussion of one kind of functionalism: Putnam's computational functionalism. But it is enough of a story to discern what critics of functionalism (such as Searle, Block, and Shoemaker, among others) find perhaps most deficient with this picture of mind. The deficiency is this: a functionalist account of mind, construed in this way, seems to leave little (if any) explanatory space for any sort of intrinsically qualitative element in conscious experience or the individual mental states constitutive of consciousness. In other words, the claim is that functionalism purports to provide an account of mind that leaves out what is perhaps the mind's most important feature: what it feels like to actually have a mind.

Two of the more famous arguments against functionalism, the "inverted spectrum" thought-experiment and the "absent qualia" problem, highlight this purported deficiency. ${ }^{3}$ Under the "inverted spectrum" argument, two subjects can be functionally isomorphic to one another but enjoy qualitatively inverted color-experiences. Thus Ray and Rich can be visually experiencing the same tomato, but while Ray is having a genuine red-sensation, Rich is actually having a green-sensation (though he terms this sort of green color sensation "red," since he doesn't know any better. Rich has always seen green where others see red, and thus assumes that his "green" is what everyone else sees when they speak of "red"). According to functionalism, such a scenario is inconceivable by definition: if two subjects are functionally isomorphic, they are necessarily in the same mental state. But the critic argues that Rich and Ray's scenario is entirely conceivable, and thus functionalism is false.

Similarly, advocates of the "absent qualia" problem argue that the relevant functional organization of consciousness can be instantiated in different physical systems (again, a robot, alien, or the population of China) but that the "functional states" instantiated by these systems would surely lack the rich phenomenal feels that individuate our mental states from one another as we experience them. Surely, the claim goes, we would not attribute full-blown consciousness to the population of China as a whole, even if it exhibited the "appropriate" functional organization to instantiate consciousness. The qualitative character of experiential states would thus be absent in these cases of functionally-specified "consciousness." Both the "inverted spectrum" and "absent qualia" objection in this way purports to establish the possibility of systems or creatures that are functionally identical to human minds but which lack the appropriate phenomenal features of experience. 
The arguments discussed above purport to show that a functionalist portrayal of consciousness fails to answer the question of why consciousness feels the way that it does. (The functionalist account also strikes many counterintuitive-particularly the multiple realizability thesis, according to which a large grouping of tin cans, for example, could qualify as conscious, assuming they were arranged in the appropriate causal-functional configuration-but I leave this aspect of the discussion aside). ${ }^{4}$ Put bluntly, critics argue that functionalist theories of mind neglect the essential feature of the mental that makes consciousness what it is: the intrinsic phenomenal feel of what it is like to actually be conscious and experiencing. Yet another way of putting the matter is that the functionalist assimilates the phenomenal (the way consciousness feels) to the causal (what consciousness does as the explanatory basis of behavior), and thus provides only a one-sided explanation of the mental. ${ }^{5}$ Of course, many in the continental philosophical tradition, including Sartre, have long stressed the need for an account of mind that does justice to the phenomenal aspect of consciousness experience as lived. But many functionalists-perhaps fearing that any attempt to preserve the phenomenality of consciousness while conjoining it with a physicalist account of the mental will necessarily entail an unacceptable dualism-have appeared to critics as all-too-ready to eject the very feature of consciousness that makes it such a special phenomenon.

Functionalists, of course, are not without rejoinders to the objections briefly discussed above. However, the limited scope of this paper does not encompass a survey of classical arguments for and against functionalism. ${ }^{6}$ Rather, I am concerned to develop the specifically Sartrean challenge that can be levied against all forms of functionalism, generally construed. Again, functionalism writ large denies the existence of intrinsic features of experience, instead characterizing mental states in term of their causal-functional roles and relations. I contend that Sartre argues to the contrary for at least one necessarily intrinsic feature of experience: prereflective consciousness. Therefore, this important notion-so very critical to Sartre's phenomenological ontology of consciousness developed within Being and Nothingness-can be summoned against general functionalist accounts of mentality.

I would now like to develop this last claim more carefully by utilizing Sartre's notion of prereflective consciousness. Specifically, I will argue that pre-reflective consciousness is an intrinsic feature of all conscious experience that ( 1 ) individuates different mental states without appealing to their causal-functional basis, and that it is 
furthermore (2) a feature of experience that provides, at least partially, the basis for the phenomenal aspect of consciousness (again, without appealing to casual-functional explanation).

\section{Sartre on Prereflective Consciousness}

In Being and Nothingness, Sartre distinguishes pre-reflective consciousness from reflective consciousness. Reflective consciousness, Sartre argues, is an act of consciousness in which consciousness deliberately turns back on itself and "the reflecting consciousness posits the consciousness reflected on, as its object" (1956: 12). Yet this reflexive "self-objectifying" movement of consciousness is a founded mode of consciousness, according to Sartre. Reflective consciousness arises from a more primitive pre-reflective self-consciousness. And reflective consciousness is therefore a secondary or derivative act, founded in this pre-reflective consciousness. For in order to avoid an infinite regress of potentially self-reflexive acts ("I am aware that I am cold," and "I am aware that I am aware that I am cold," and "I am aware that I am aware that I am aware that I am cold," ad infinitum), Sartre contends that there must be a point at which consciousness cannot turn upon itself and take itself (and its acts and their contents) as objects. The standpoint of pre-reflective consciousness is just this terminal or bedrock point. Pre-reflective consciousness thus makes possible reflective consciousness (Wider, 1997: 45). Sartre argues that "every positional consciousness of an object is at the same time a non-positional [or pre-reflective] consciousness of itself" (1956: 13). And this pre-reflective self-consciousness, as an intrinsic feature of all conscious experience, needs to be considered "not as a new consciousness, but as the only mode of existence which is possible for a consciousness of something" (1956: 14).

The kernel of Sartre's discussion most salient to our present concerns is the claim that even pre-reflective consciousness-which is the bare consciousness of something other than itself (i.e., an object of which it is conscious)-is self-aware. According to Sartre prereflective consciousness is a mode of self-awareness in which consciousness, as aware of an object, is simultaneously aware of not being that object of which it is aware. This awareness of not being that of which it is aware-again, the specific object of an act of consciousness-is a primitive self-awareness, Sartre contends. It is an intrinsic feature of all experience. And therefore even pre-reflective consciousness, which grounds reflective consciousness and is thus 
the primal level of consciousness, exhibits self-awareness. Put simply, consciousness is self-aware all the way down. (This understanding is what motivates Sartre's larger well-known claim concerning the absolute translucency of consciousness). If this prereflective consciousness were not operative in all conscious acts, Sartre contends, consciousness could conceivably be conscious of an object without being conscious of itself as conscious of an object-rendering an unconscious consciousness-which he insists is a patent absurdity, logically and phenomenologically incoherent. Thus this implicit selfawareness is an irreducible feature of all conscious experience, according to Sartre. It is both a logical as well as phenomenological feature of consciousness, and individuates mental states without recourse to their causal-functional origins. Thus it is an intrinsic feature of experience that eludes functional explication. The claim will be developed more fully in a moment.

A brief tangent here. Sartre is not the only prominent thinker to argue for a primitive self-awareness as an intrinsic feature of all conscious experience. Kant offers a somewhat similar (though certainly less developed) understanding of primitive self-awareness as that found in Sartre. Like Sartre, Kant claims that simply recognizing an object of consciousness is sufficient for recognizing that $I$ am recognizing an object, that $I$ am aware of the experience as mine. This implicit self-awareness in the Critique of Pure Reason is referred to as a kind of "pure self-consciousness":

Thus the subject of the categories cannot, by thinking them, obtain a concept of itself as an object of the categories; for in order to think them, it must take its pure self-consciousness, which is just what is to be explained, as its ground. (B422)

By designating this form of self-awareness as "pure," Kant anticipates Sartre in arguing that this bedrock or primitive self-awareness cannot take itself as an object. Rather, it is the condition of possibility for taking anything as an object of experience. ${ }^{7}$ Thus Kant's "pure self-consciousness," a primitive self-awareness that accompanies all conscious experience, is not an object of reflective consciousness: "Now it is indeed very illuminating that I cannot cognize as an object itself that which I must presuppose in order to cognize an object at all" (A402). ${ }^{8}$

To return to the main thread of the argument: I have argued that all consciousness, according to both Kant and Sartre-and pace functionalism-harbors a primitive self-referentiality as an intrinsic feature of experience. Importantly, this implicit self-awareness is both a logi- 
cal as well as phenomenological feature of experience that is independent of causal-functional explanations. In assimilating the phenomenal to the causal-functional, functionalism mistakenly ignores this intrinsic feature of experience. Thus functionalism overlooks an essential feature of the mental and is explanatorily inadequate.

But what about the phenomenal aspect of conscious experience? Can Sartre's notion of pre-reflective consciousness contribute an explanation of the qualitative feel that, according to common sense, would seem to individuate different mental states? And can it demonstrate that functionalism's jettisoning of this phenomenal feel of consciousness is misguided? I suggest that it can. The argument goes like this. Sartre's implicit self-awareness (or pre-reflective consciousness) founds the intrinsic phenomenality of mental states. It does so in the following way. Within an occurrent mental state there is an irreducible "givenness" that somehow marks it as my own. That is, this irreducible givenness is the first-personal presentation of an experience to me. And while a possible object of experience can appear for multiple subjects-a red apple, for example, is intersubjectively accessible in that it can perceptually present itself to others, each assuming a different phenomenological vantage-point-the first-personal givenness of $m y$ experience of an object is given only to $m e$. Therefore, these first-personal experiences are characterized by their phenomenal quality that tells me "what it is like" to have a particular experience-and most importantly, tells me "what it is like" for me to have a given experience from my phenomenological perspective. (This notion of "phenomenological perspective" is important, and will be discussed more in a moment). Furthermore, it is because of this subjective feel of this first-personal givenness that we can speak sensibly of what it is like for another person to have their own unique experience of a tree, a childhood memory, or a pleasantly smoky single malt scotch. We understand the reports of others who claim to have had similar experiences because we are able to set them next to our own immediate awareness of the first-person "feel" of having had similar experiences ourselves. ${ }^{9}$

Generalizing from this, we can say that there is something that it's like to have such experiences because there's something that it's like to be pre-reflectively self-aware and to have such experiences. While redness is a property of the perceived apple-the thing "out there" in the world, so to speak - the self-manifestation of the redness of the apple in my individual experience of it is not. Therefore there is an intrinsic feature of experience that is not reducible to the objects of our experience. And this irreducible feature, how the redness of 
the apple manifests itself specifically to me, as a self-aware experiencing subject embodying a particular phenomenological perspective, deals not with properties of objects of consciousness but rather with intrinsic properties of an experience given with a first-personal immediacy to me, a self-aware experiencing subject. Thus there are properties intrinsic to the presence or mode of presentation of objects-specifically, in their first-personal immediacy, their immediate givenness to me via a particular mode of presentation (such as seeing, hearing, tasting, smelling, touching, etc.) —which exist apart from intentional objects and our causal-functional relations with them. These intrinsic properties of experience resist tidy functional explanation.

There is a bit of a wrinkle, however. It might be objected that I have provided an overly subjectivist rendering of Sartre's account of phenomenal qualities of experience. ${ }^{10}$ In other words, the objection goes like this. For Sartre, consciousness is literally nothing. It is utter translucency, emptiness. Thus, whatever content consciousness hasincluding intentional objects, such as a red apple-is not, strictly speaking, in consciousness. For there is nothing for conscious content to be in, in the first place! Again, consciousness is emptiness. Therefore, to posit the notion of an intrinsic feature of experience, or a phenomenal property of consciousness somehow intrinsic to conscious states, is to miss Sartre's point entirely. For according to Sartre, all properties of consciousness, including phenomenal properties or subjective qualities of experience, are rather really qualities of the world "out there": the things and states of affairs, in themselves, towards which consciousness is directed. Consciousness is literally nothing over against the transcendent objects that it reveals. It has no being and no content other than its fundamental openness or directedness (the various modes of its intentional relationships) that disclose transcendent objects of consciousness as being for the particular experience of a conscious subject. But consciousness is nothing beyond this fundamental openness or world-directedness. And once more, whatever properties the things and states of affairs of the world are experienced as having are intrinsic to the things and states of affairs themselves, not consciousness. This radical reversal of idealism-where the content of consciousness, including its phenomenal or subjective qualities, are out in the world-is perhaps Sartre's sharpest point of divergence from both Kant and Husserl's egological models of consciousness.

Several salient quotes from Being and Nothingness seem to support this objection. For example, Sartre writes that "Too often, quality has been conceived as a simple subjective determination, and its 
quality-of-being has then been confused with the subjectivity of the psychic" (1956: 257). Against this subjectivist or representationalist rendering of perception, Sartre insists that "the yellow of the lemon is not a subjective mode of apprehending the lemon; it is the lemon" (1956: 257); and later: "The odor which I breathe in ... even before I have referred to it an odorous object, is already an odor-being and not a subjective impression" (1956: 259). Thus, a perceptual quality, such as redness, yellowness, or odorousness "can indeed appear to a subjectivity, but it can not be inserted in the woof of that subjectivity ..." (1956: 259). In other words, whatever phenomenal or subjective qualities we experience are qualities that inhere in the objects themselves, and not within some sort of inner mental realm housing ideas or representations of theses qualities. All appearances of things and states of affairs to consciousness-yellow lemons, red apples, odorous smells slithering in through an open window-are thus transcendent, nonmental entities. ${ }^{11}$

Yet we nevertheless experience phenomenal appearances with an immediate, noninferential, first-person givenness that gives phenomenal qualities an "absolute proximity" to us, an "absolute proximity ... without either giving or refusing itself" (1956: 259). Sartre then adds that this absolute first-person proximity nonetheless "implies a distance" (1956: 259). Thus, "sense quality is a presence perpetually out of reach" (1956: 258). Elaborating this phenomenal tension, he continues:

Quality is the indication of what we are not and of the mode of being which is denied to us. The perception of white is the consciousness of the impossibility on principle for the For-itself to exist as color-that is, by being what it is. (1956: 259)

If someone should ask now how it happens that the "this" has qualities we should reply that actually the this is released as a totality on the ground of the world and that it is given as an undifferentiated unity. It is the for-itself which can deny itself from various points of view [my emphasis] when confronting the this ... For each negating act by which the freedom of the For-itself spontaneously constitutes its being, there is a corresponding total revelation of being "in profile"... [which] is nothing but a relation of the thing to the For-itself, a relation realized by the Foritself. (1956: 259)

The water is especially murky here, so let's begin simply. There are number of interesting consequences of Sartre's view of consciousness developed in the above remarks. For one, Sartre insists that, since nothing is actually in consciousness, there is no ontological basis for positing the existence of inner ideas, impressions, representations, or sense data that serve as the true objects of experience. 
Rather, in an occurrent experience, we have direct, unmediated and noninferential access to the things and states of affairs that we take ourselves to be experiencing. Consciousness, as a fundamental world-directed openness, is directed out towards real things in the world, as they are in themselves. Sartre thus affirms a theory of direct perception.

Additionally, it seems as though for Sartre all features of consciousness-including its phenomenal properties-are actually features of the world (and things in it) toward which consciousness is directed. Put simply, the feels of consciousness are actually distributed across the objects themselves. The phenomenal feels of "yellowness" and "sourness" are features of the lemon, and not "inner" features of consciousness. But how is this so? How can all consciousness be self-conscious (an "absolute proximity") and yet at the same time be utterly empty of content-including phenomenal properties?

Again, Sartre's reconciliation of these tensions is not particularly clear. In a moment, I'll spell out how I think these tensions in fact can be reconciled-though my solution is not one we find sufficiently developed in Sartre. To understand Sartre's view here, recall that every act of consciousness, for Sartre, consists of a negation of consciousness in the face of that towards which consciousness is directed. Consciousness is always negated by that which it is not. This is consciousness "deny[ing] itself ... when confronting the this" (1956: 259), where "the this" is that of which consciousness is aware. And it is in this self-negation that consciousness "spontaneously constitutes its being" (1956: 259). A logical and phenomenological feature of this self-negation, then, is pre-reflective self-awareness: a tacit self-awareness that, at each moment of experience, affirms that I am not that which I am currently aware of. This holds for phenomenal properties, too. For though I am aware of the yellowness and the sourness of the lemon-and moreover, prereflectively aware that this yellowness and sourness, as experienced, is $m y$ phenomenal experience given immediately to me-I am simultaneously aware that that the lemon itself possesses these same qualities. These qualities are "released" by the lemon for me. But they are phenomenal properties that nonetheless do not exist in me (in any sort of intramental representation, sense data, etc.) but are rather qualities of the lemon in-itself.

Is this enough? Does this rendering offer an adequate account of how preflective self-awareness can both be an intrinsic feature of all conscious states and, at the same time, preserve their phenomenality without importing some sort of problematic intramental 
entity (representations, sense data, ideas, impression, etc.) within which phenomenal qualities are purportedly realized? It's not clear that it does. In the next section, I discuss a manner in which some of the tensions and difficulties in Sartre's view might be untangled and clarified.

\section{Back to the Body: Broadening Sartre's Notion of Prereflective Consciousness}

In this final section, I would like to offer a way in which Sartre's notion of pre-reflective consciousness might be improved. Specifically, I argue that by deepening the notion of pre-reflective consciousness to encompass the sensorimotor structures of our world-engaged embodied action-and furthermore acknowledging that these sensorimotor capacities and bodily skills also harbor an implicit self-awareness-we accomplish two things. First, we provide an account of self-awareness more consonant with the phenomenology of our embodied coping, and clarify some of the conceptual and phenomenological difficulties referenced in the previous section. Secondly, we have sharpened the manner in which this notion can be summoned as a critique of functionalism.

I will be brief here. My basic criticism in this final section might strike some as a tad ironic. Namely, I argue that Sartre, noted philosopher of the body, fails to take seriously enough the relationship between his central claims that all consciousness is ( 1 ) embodied and (2) self-aware. While he emphasizes at length this latter feature of consciousness (its self-awareness), his formulation of how consciousness is self-aware "all the way down" (which I've been discussing in the prior sections) neglects several crucial aspects of the way that an embodied consciousness engages with its world as a bodily subject. Thus his notion of pre-reflective consciousness remains overly-cognitivist, and needs to be extended to encompass pre-reflective bodily skills (possibilities for action and movement) and the implicit self-awareness that is part of their basic structure. ${ }^{12}$

Admittedly, Sartre is not totally silent on the idea of bodily selfawareness. Part 3 of Being and Nothingness contains his most explicit consideration of the lived body: the body-subject, as opposed to my body experienced as an object for another, which is an alienation from the more basic experience of my body-as-subject. He writes that "because the body is the point of view on which there cannot be a point of view ... the body belongs then to the structures of the 
non-thetic self-consciousness" (1956: 434). Yet Sartre immediately qualifies this claim by arguing that the body cannot be identified "purely and simply" with non-thetic consciousness (1956: 434). For "non-thetic self-consciousness is self-consciousness as the free project towards a possibility which is its own; that is, in so far as it is the foundation of its own nothingness" (1956: 434). And thus "Non-positional consciousness is consciousness (of the) body as being that which it surmounts and nihilates by making itself consciousness-i.e., as being something which consciousness ... passes over in being what it had to be. In short, consciousness (of) the body is lateral and retrospective; the body is the neglected, the "passed by in silence" (1956: 434).

Again, Sartre is a bit difficult here. But it seems that his claim is the body-or more precisely, our basic self-awareness of ourselves as embodied within a world-is what both discloses the fact that consciousness exists as embodied in its world, as well as being that which must be "nihilated" for consciousness to become aware of the world in which it is embodied. Bodily self-awareness at this basic level is only present by its absence (once it is nihilated by the upsurge of consciousness into the world). In other words, my body opens up the world as an arena of potential action and movement, but to realize these bodily potentials, I must inhabit or "live-through" my body so transparently that it fades to pure absence while I live, act, and move within the world.

Sartre's position harbors some important phenomenological insights into the prereflective structure of bodily action and clearly anticipates some of Merleau-Ponty's later related insights. However, I think Sartre's more general approach here is mistaken. Briefly, here's why. When I have an experience of the world (say, looking at a rose bush in my garden), the content of my experience always presents itself from a particular phenomenal perspective or vantage point. (Recall Sartre's earlier point that "It is the for-itself which can deny itself from various points of view [my emphasis] when confronting the this" (1956: 259). This perspectival aspect of the content of my experience is specified by where I am in relation to the object of my experience. It also specified by where I could possibly $b e$, if I decide to take three steps to the left, for instance. But this relation to the objects of my experience-a spatial relation-is specified by my bodily relation to these objects (e.g. the direction of the sound of a car suddenly backfiring is specified in relation to my body, and I become aware of it as "slightly behind me and to my left"; the rose bush is seen as "directly in front of me"). This 
perspectival self-awareness is a bodily self-awareness that is operative without conceptual or reflective articulation. It is an implicit selfawareness, but not simply a cognitive self-awareness, or a matter of the for-itself taking up a perspective on the world. It is first and foremost a bodily self-awareness. In other words, it is a proprioceptive self-awareness of the body's potential for action and movement. ${ }^{13}$

Thus the orientational structure of my perceptual field always harbors an implicit self-referentiality to the embodied perspective I take on the world and the experiences I have of the things in it from this embodied perspective. The content of my experience is coupled to the fact of my embodied agency: my potential for action and movement. Importantly, once more, this bodily self-referentiality is not equivalent to a higher-order cognitive self-reflexivity, however, but is in fact more phenomenologically basic. (And thus we can also speak of certain animals as enjoying this bodily self-referentiality). The roses look a certain way to me from here, where "here" denotes a specific spatial relationship to the roses that I have in virtue of where I am presently standing. Sartre's overly-mentalist formulation of prereflective consciousness thus overlooks the extent to which my body inhabits this "egocentric space" (as Gareth Evans [1982] refers to it) that I am here describing. Furthermore, this "egocentric space" not only refers to my present spatial relationship with respect to the object of my experience, but moreover to any potential bodily perspectives I might assume (leaning over the top of bush, lying on my back beneath it, kneeling behind it), based upon having a body with the specific sensorimotor capacities and bodily skills that afford possibilities of movement and action. This self-awareness of my being a "biological body" that stands in a determinate (but malleable) perspectival relation with the objects of my experience is part of the basic structure of every experience-and it exists prior to my cognitive self-consciousness. Yet Sartre says little of our "biological body" and its generation of this "egocentric space"-through actions and movements both realized and implicitly recognized as possible, given the constraints of changing action-contexts-as I've described these features of our experience. Even if a more focused consideration of our "biological" body does not fit into Sartre's immediate phenomenological concerns (as he might respond to my charge), such a consideration would nonetheless certainly help to fill out a more robust account of the structure of our embodied agency in the world when coupled with Sartre's phenomenological investigations. One can acknowledge the contributions rendered by a consideration of our "biological" body without collapsing the biological body's lived 
phenomenology back into a purely materialist account of consciousness. But Sartre's insistence on the rigid ontological division between the subject-body (its phenomenology) and body-as-objectfor another (its physical or "biological" aspects) seemingly precludes this dual consideration of embodied consciousness.

Of course, this final criticism does not in any way lessen Sartre's relevance to contemporary philosophy of mind. Establishing this final point was perhaps this paper's foremost goal. If anything, the discussion which emerged from Sartre's views-including its shortcomings-only serves to reaffirm his immediate significance to ongoing discussions of the nature of embodied consciousness and experience. And Sartre's important reflections on consciousness thus deserve a readership more concerned with exploring the mysteries of consciousness as lived than with preserving analytical and continental methods as allegedly autonomous and self-sufficient approaches to mind.

Joel W. KRUeger is a doctoral student in philosophy at Purdue University. He presently teaches philosophy at Southern Illinois University, Carbondale, where he is writing a dissertation on "pure experience" in William James and Kitaro Nishida, and this notion's relevance to several core issues philosophy of mind and cognitive science.

\section{Notes}

1. Many thanks to Steve Hendley for helpful comments on and discussion of an earlier draft of this essay. Thanks also to two anonymous reviewers for their insightful suggestions.

2. In the philosophy of mind and cognitive science literature, "folk psychology" refers to the pre-philosophical views the lay person has about the nature of the mind and mental states, most notably those having to do with the prediction and explanation of behavior. Examples include beliefs like mental states are inner phenomena, damaging a particular part of the body causes pain in that area and people who are angry frown.

3. See Ned Block's “Troubles with Functionalism," in Block (1980) for a discussion of these objections.

4. For an extended discussion and criticism of the multiple realizability thesis, see Shapiro (2004).

5. David Chalmers (1996) makes this same point. See pgs. 11-16. 
6. For responses to the inverted spectrum and absent qualia arguments, see Dennett (1978), Van Gulick (1989), and Shoemaker (1994).

7. For a further discussion of both Sartre and Kant on this issue (including some important points of divergence not here considered), see Wider (1997). For a more extended consideration of Kant's understanding of transcendental selfawareness, see Brook (1994).

8. For the sake of clarification, it is important to note that Sartre does part with Kant in some important ways concerning the larger significance of prereflective consciousness for understanding mind and experience. Indeed, in The Transcendence of the Ego: An Existentialist Theory of Consciousness (1960), Sartre offers an extended critique of the transcendental commitments of both Kant's and, especially, Husserl's ego-logical approaches to consciousness. (Transcendence of the Ego is, of course, largely directed at Husserl). Therefore, it is important not to overstate the affinities between the three men on this point. Once more, however, to venture too far astray here would take us into complicated but important interpretive terrain not directly relevant to present concerns. My claim here is simply that Kant and Sartre-despite their substantive differences-both draw attention to what Sartre terms "pre-reflective consciousness" as a necessarily intrinsic feature of all experience. See Mensch (2001) for an analysis of Husserl's similar thoughts on this issue.

9. See Zahavi (1999) for an extended analysis the various modes of self-awareness, including prereflective self-awareness, informing consciousness and experience. Zahavi's careful analysis was very helpful in motivating the arguments of this paper.

10. This important objection was brought to my attention by an anonymous reviewer of this essay.

11. These and other quotes seem to cast Sartre as something of an externalist-and there is probably something to this. For an interesting elaboration of Sartre's view here and its relation to contemporary externalist views of mind, see Rowlands (2003).

12. The argument in this section is very much influenced by Alva Noë's sensorimotor-based enactive account of consciousness in Noë (2004).

13. There is empirical support, culled from recent research in developmental psychology, for thinking that a proprioceptive self-awareness of this sort is present from birth. See in particular Meltzoff and Moore (1977), Meltzoff (2005), and Gallagher (2005), especially chapter 3 .

\section{References}

Block, N. (1980), Readings in the Philosophy of Psychology, Volumes 1 and 2 (Cambridge: Harvard University Press).

Brook, A. (1994), Kant and the Mind (Cambridge: Cambridge University Press). 
Chalmers, D. (1996), The Conscious Mind: In search of a fundamental theory (Oxford: Oxford University Press).

Dennett, D. (1978), Brainstorms (Montgomery: Bradford Books).

Evans, G. (1982), The Varieties of Reference (New York: Oxford University Press).

Gallagher, S. (2005), How the Body Shapes the Mind (Oxford: Oxford University Press).

Meltzoff, A. (2005), "Imitation and Other Minds: The 'Like Me' Hypothesis," in Perspective on Imitation: From Neuroscience to Social Science, ed. S. H. a. N. Chater (Cambridge: MIT Press).

Meltzoff, A. and Moore, K. (1977), "Imitation of facial and manual gestures by human neonates," Science, 198, 75-78.

Mensch, J. (2001), Postfoundational Phenomenology: Husserlian reflections of presence and embodiment (University Park: Pennsylvania State University Press).

Noë, A. (2004), Action in Perception (MIT Press).

Putnam, H. (1967), "Psychological Predicates," in Art, Mind, and Religion, eds. W. H. Capitan and D. D. Merill.

Rowlands, M. (2003), Externalism: Putting Mind and World Back Together Again (Ithaca: McGill-Queen's University Press).

Sartre, J.-P. (1956), Being and Nothingness, trans. H. E. Barnes (New York: Washington Square Press).

Sartre, J.-P. (1960), The Transcendence of the Ego: An Existentialist Theory of Consciousness (New York: Hill and Wang).

Searle, J. R. (1992), The Rediscovery of the Mind (Cambridge: MIT Press).

Searle, J. R. (1997), The Mystery of Consciousness (New York: New York Review of Books).

Shapiro, L. (2004), The Mind Incarnate (Cambridge: MIT Press).

Shoemaker, S. (1984), Identity, Cause, and Mind (Cambridge: Cambridge University Press).

Van Gulick, R. "What Difference Does Consciousness Make?” Philosophical Topics, 17.

Wider, K. (1997), The Bodily Nature of Consciousness: Sartre and contemporary philosophy of mind (Ithaca: Cornell University Press).

Zahavi, D. (1999), Self-Awreness and Alterity: A Phenomenological Investigation (Evanston: Northwestern University Press). 